BRUNA RACHEL DE PAULA DINIZ

A revista íntima e as visitantes de estabelecimentos prisionais: uma análise à luz dos princípios constitucionais penais

Dissertação de Mestrado

Orientadora: Professora Associada Dra. Mariângela Gama De Magalhães Gomes

UNIVERSIDADE DE SÃO PAULO

FACULDADE DE DIREITO

SÃO PAULO - SP

2018 


\title{
A revista íntima e as visitantes de estabelecimentos prisionais: uma análise à luz dos princípios constitucionais penais
}

\begin{abstract}
Dissertação apresentada à Banca Examinadora do Programa de Pós-Graduação em Direito, da Faculdade de Direito da Universidade de São Paulo, como exigência parcial para obtenção do título de Mestre em Direito, na área de Direito Penal, Medicina Forense e Criminologia sob orientação da Professora Associada Dra. Mariângela Gama De Magalhães Gomes.
\end{abstract}

\section{UNIVERSIDADE DE SÃO PAULO \\ FACULDADE DE DIREITO \\ SÃO PAULO - SP


Autorizo a reprodução e divulgação total ou parcial deste trabalho, por qualquer meio convencional ou eletrônico, para fins de estudo e pesquisa, desde que citada a fonte.

\author{
Catalogaçāo da Publicaçāo \\ Serviço de Biblioteca e Documentação \\ Faculdade de Direito da Universidade de São Paulo
}

Diniz, Bruna Rachel de Paula

A revista intima e as visitantes de estabelecimentos prisionais: uma análise à luz dos principios constitucionais penais / Bruna Rachel de Paula Diniz ; orientadora Mariângela Gama De Magalhães Gomes -Săo Paulo, 2018.

$216 \mathrm{p}$.

Dissertação (Mestrado - Programa de Pós-Graduação em Direito Penal, Medicina Forense e Criminologia) - Faculdade de Direito, Universidade de Sāo Paulo, 2018.

1. Revista Intima. 2. Visitantes de Prisöes. 3. Princípios Constitucionais Penais. 4. Estigma. 5. Violência Institucional de Gênero. I. Gomes, Mariângela Gama De Magalhães, orient. II. Título. 
DINIZ, Bruna Rachel de Paula.

A Revista Íntima e as Visitantes de Estabelecimentos Prisionais: uma análise à luz dos princípios constitucionais penais.

Dissertação apresentada à Faculdade de Direito da Universidade de São Paulo como exigência parcial para obtenção do título de Mestre em Direito.

Aprovado em:

Banca Examinadora

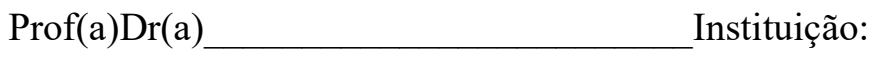

Julgamento: Assinatura:

$\operatorname{Prof}(\mathrm{a}) \operatorname{Dr}(\mathrm{a}) \_$Instituição:

Julgamento:__ Assinatura:

$\operatorname{Prof}(\mathrm{a}) \operatorname{Dr}(\mathrm{a}) \_$__ _ _ _ _ _ _ _ _ _ _ _ _ _ _ _ _

Julgamento:__ Assinatura:

$\operatorname{Prof}(\mathrm{a}) \operatorname{Dr}(\mathrm{a}) \_$Instituição:

Julgamento:__ Assinatura: 
A minha mãe, Cleusa e ao meu pai, Carlos. 


\section{AGRADECIMENTOS}

Primeiramente agradeço aos meus pais, Cleusa e Carlos, por todo o apoio que me deram e me dão em conjunto todos os dias. A minha mãe, por ser a primeira mulher feminista em minha vida, meu exemplo de responsabilidade e humanidade e ao meu pai, um companheiro nas alegrias e percalços da vida, além do primeiro abraço na aprovação no vestibular (olhe onde chegamos!).

Agradeço também aos meus avós, Marina, José, Neusa e Nivaldo, por me darem o maior amor que alguém poderia receber. Não acredito que exista alguém que acredite mais em mim do que vocês. E à Dora, para quem o lugar de tia avó me pareceu pequeno dentro da imensidão de histórias que dividimos desde que eu tenho lembranças.

À Professora Mariângela Magalhães, minha referência de comprometimento à docência, agradeço pelo olhar atento a meus trabalhos desde a graduação e aos inúmeros apontamentos feitos ao longo das etapas de pesquisa e escrita dessa dissertação.

Sou também muito grata às Professoras Ana Gabriela Braga e Helena da Costa pelas considerações feitas no Exame de Qualificação, as quais permitiram a definição clara dos objetivos desse trabalho e reafirmaram a importância em realizar uma pesquisa comprometida com a epistemologia feminista. Também ao Professor Marcus Orione, por algumas das melhores aulas que tive durante o curso de Mestrado.

Aos funcionários da Faculdade de Direito da Universidade de São Paulo meu agradecimento pelos serviços prestados, pelas conversas nos corredores e pelo carinho diário. Em especial à Lúcia e ao Pariol, por muitos anos figuras queridas da seção de alunos; à Simone, alegria de todos os almoços; e a Priscila, sempre à espera das minhas novidades.

Aos membros do Serviço de Assessoria Jurídica Universitária (SAJU-USP), por dividirem comigo os primeiros sonhos e angústias que acompanham a militância e por serem a origem das primeiras ideias que levaram a esse trabalho. 
À Mariana, minha grande companheira na vida, tanto nas horas em que ela é maravilhosa, como nos momentos em que a realidade perde todo o sentido. Muito obrigada por acreditar em mim sempre e por me acompanhar nos caminhos tortuosos de ser mulher no mundo de hoje.

Também agradeço às pessoas queridas que me acompanharam durante os anos de escrita desse trabalho. Ao Guilherme pelas correções e pelo enorme carinho nas horas difíceis da escrita e da vida. À Nathália, pelo companheirismo nos espaços áridos da Academia. Ao Carlos e ao José Paulo, por dividirem comigo cotidianamente a experiência do Mestrado. Ao Bruno, pelas leituras atentas e pelo apoio nas idas a campo. Finalmente, aos meus irmãos, Carlos Henrique e José Eduardo pelos questionamentos cotidianos sobre o andamento do trabalho e pela ajuda na sua fase final de elaboração.

Um imenso agradecimento a todas as mulheres que conversaram comigo nas filas de visita e possibilitaram tantas vezes que essa pesquisa fosse realizada. Certamente sem elas esse trabalho seria completamente diferente.

Por fim, ao Deutscher Akademischer Austauschdienst (DAAD), pela bolsa de estudos concedida que permitiu a realização de parte dessa pesquisa no Instituto Max Planck de Direito Penal e Criminologia. 


\section{How to wear your mother's lipstick}

You must wear it like she wears disappointment on her face

You find the black tube inside her beauty case, where she keeps your fathers old prison letters, you desperately want to look like her.

You go to the bathroom to apply the lipstick, somewhere no one can find you your teeth look brittle against the deep red slickness

you smile like an infant, your mouth is a wound

you look nothing like your mother you look everything like your mother.

Your mother is a woman and women like her cannot be contained. 


\section{RESUMO}

DINIZ, Bruna Rachel de Paula. A Revista Íntima e as Visitantes de Estabelecimentos Prisionais: uma análise à luz dos princípios constitucionais penais. Dissertação (Mestrado) Faculdade de Direito, Universidade de São Paulo, São Paulo, 2018.

A revista dos visitantes de estabelecimentos prisionais no Brasil foi por décadas realizada por meio da busca pessoal íntima, que pressupunha o desnudamento completo e a inspeção minuciosa das cavidades corporais. A partir dos anos 2000, surge no debate público uma série de críticas a prática, que se torna proibida nacionalmente com a aprovação da lei federal $\mathrm{n}^{\circ} 13.271 / 2016$. Nesse cenário, o presente trabalho tem como escopo compreender o processo de extinção formal da revista íntima nos estabelecimentos prisionais brasileiros, a partir das contribuições da Dogmática Penal e da Criminologia. Para tanto, a pesquisa parte das definições acerca do Instituto da Busca Pessoal e traça um perfil do grupo de pessoas a ela submetidas ao ingressarem nas prisões brasileiras. Com isso, analisa-se a prática à luz das Garantias Constitucionais Penais afetas à questão: a Intranscendência da Pena, a Dignidade Humana e a Legalidade. A seguir é proposta uma segunda visão sobre as visitantes e revista íntima, sob a perspectiva de autores do Interacionismo Simbólico, da Criminologia Crítica e da Teoria Feminista. Com essas constatações teóricas consolidadas, passa-se ao estudo do processo histórico de proibição do procedimento nas diversas instâncias de poder do Estado Brasileiro, impulsionadas pela atuação da Sociedade Civil Organizada e como tais mudanças repercutiram no Estado de São Paulo. Ao final, as conclusões parciais do trabalho são confrontadas com o olhar de visitantes de Centros de Detenção que viveram a substituição da revista íntima por escâneres corporais.

Palavras-chave: Revista Íntima. Visitantes de Prisões. Princípios Constitucionais Penais.

Estigma. Violência Institucional de Gênero. 


\begin{abstract}
DINIZ, Bruna Rachel de Paula. The strip-search procedure and the prison visitors: an analysis based on criminal constitutional principles. Dissertation (Master) Law Faculty, University of Sao Paulo, Sao Paulo, 2018.

The security protocol concerning prison visitors in Brazil was for decades based in stripsearch procedures that involved a meticulous search of all body cavities undertaken by prison guards. Since the year 2000, a series of critics has been made against the procedures which lead to its prohibition with the approval of the federal law $n$. 13.271/2016. In this scenario, the present work aims to comprehend the process by which the strip-search procedures were extinguished through the contributions of Criminal Law and Criminology. Therefore, this dissertation starts with the definition of Personal Search and draws a general profile of the group that is studied - the inmates' families. Following that, the Brazilian strip-search carceral procedures are studied in the perspective of three Constitutional Criminal Principles: Individual Nature of Penalties, Human Dignity, Legality. In the next session, the subject is analyzed within the perspective of Authors from the Symbolic Interactionism, the Critical Criminology and the Feminist Theory. With these partial conclusions, the work begins to focus on the Brazilian historical process of the prohibition of strip-searched among prison visitors, in which the political activism of Civil Society Organizations played an important role. Finally, the main points of this dissertation are confronted with the perspective of inmates' families that visit two Penal Facilities in the Brazilian state of Sao Paulo, who have experienced the changes in the security protocol from the strip-searches to full-body scanners.
\end{abstract}

Keywords: Strip-Searches. Inmates' Families. Constitutional Criminal Principles. Stigma. Institutional Gender Violence. 


\section{RESUMEN}

DINIZ, Bruna Rachel de Paula. La requisa íntima y las visitantes de cárceles: un análisis desde los principios constitucionales penales. Disertación (Maestría) Facultad de Derecho, Universidad de Sao Paulo, Sao Paulo, 2018.

Las revisiones personales hechas en las visitantes de cárceles en Brasil fueron por décadas efectuadas por medio de la requisa de las partes íntimas de los familiares de presos. A partir del año 2000 surgen en el debate público una serie de críticas al procedimiento que llega a ser prohibido con la aprobación de la ley federal n. 13.271/2016. En este escenario, el presente trabajo tiene como objetivo comprender el proceso de extinción formal de las requisas íntimas en las prisiones brasileñas a través de las contribuciones de la Dogmática Penal y de la Criminología. Para eso, la investigación parte de la definición del instituto de la Búsqueda Personal y dibuja un perfil general de las personas que son a ella sometidas en el ingreso a la cárcel para visitación. Lo que es complementado por el análisis del procedimiento de requisa íntima en la perspectiva de tres Garantías Constitucionales Penales: la Personalidad de las Penas, la Dignidad Humana y la Legalidad. A continuación, se propone una segunda mirada sobre los parientes de personas presas y la requisa íntima, por la perspectiva de autores del Interaccionismo Simbólico, de la Criminología Crítica y de la Teoría Feminista. Con esas constataciones teóricas consolidadas, presentase el histórico de la prohibición del procedimiento en las diversas instancias de poder del Estado brasileño y la contribución de Organizaciones de la Sociedad Civil en él. Al final, las conclusiones parciales del trabajo son confrontadas con las opiniones de mujeres que visitan establecimientos penitenciarios en el la ciudad

de San Pablo, donde vivenciaron la sustitución de las requisas íntimas por escáneres corporales.

Palabras clave: Requisa Íntima. Parientes de Presos. Principios Constitucionales Penales. Estigma. Violencia Institucional de Género. 


\section{SUMÁRIO}

INTRODUÇÃO.

\section{CAPÍTULO 1. A REVISTA ÍNTIMA EM ESTABELECIMENTOS}

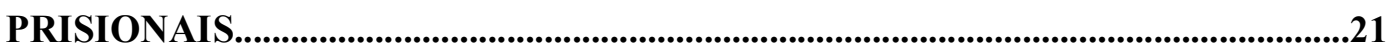

1.1. Busca Pessoal e Revista: conceito e classificação.....................................................21

1.2. A Revista Pessoal em estabelecimentos prisionais no Brasil....................................22

1.3. Quem é submetido à revista íntima: traçando um perfil de visitantes de estabelecimentos prisionais..........................................................................................................25

\section{CAPÍTULO 2. A REVISTA ÍNTIMA E OS PRINCÍPIOS CONSTITUCIONAIS}

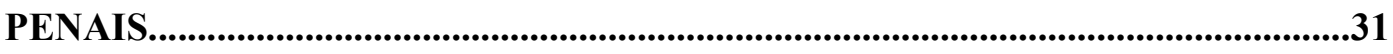

2.1. Regras, Princípios e Garantias Constitucionais: questões introdutórias.............31

2.1.1. Direitos e Garantias fundamentais.......................................................... 31

2.1.2. Regras, Princípios e sua aplicação............................................................. 32

2.2. Direito Penal e Constituição..................................................................................................37

2.2.1. Constitucionalismo e Garantismo: das proposições clássicas às

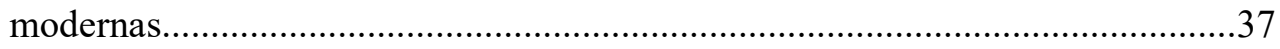

2.2.2. As formas de relação entre Direito Penal e Constituição.............................40

2.3. Os Princípios Penais Atinentes à Revista Íntima..............................................42

2.3.1. O Princípio da Intranscendência da Pena: conceito e previsão constitucional.

2.3.1.1. A Relação da Intranscendência da Pena com a Culpabilidade e a Individualização da Pena.......................................................................44

2.3.1.2. A Intranscendência da Pena e a Revista Íntima.............................46

2.3.2. O Princípio da Dignidade Humana: conceito e previsão constitucional......47

2.3.2.1. A Evolução do Conceito de Dignidade Humana............................47

2.3.2.2. A Previsão Constitucional da Dignidade Humana.........................53

2.3.2.3. Natureza Jurídica da Dignidade Humana.....................................54

2.3.2.4. A Relação da Dignidade com o Princípio da Humanidade das

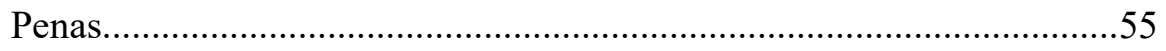


2.4. O Confronto com o Princípio da Segurança........................................................58

2.4.1. Alternativas à Revista Íntima...................................................................60

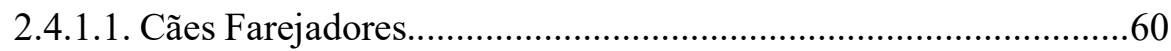

2.4.1.2. Revista no Próprio Preso.............................................................61

2.4.1.3. Visitação sem Contato entre o Preso e sua Família.......................63

2.4.1.4. Escâner Corporal........................................................................64

2.4.2. Avaliação das Alternativas com a Regra da Proporcionalidade..................67

2.5. A Garantia da Legalidade: conceito e previsão constitucional............................70

2.5.1. A Natureza Jurídica da Legalidade.......................................................75

2.5.2. A Legalidade e a Revista Íntima.............................................................77

\section{CAPÍTULO 3. AS VISITANTES DE ESTABELECIMENTOS PRISIONAIS E A}

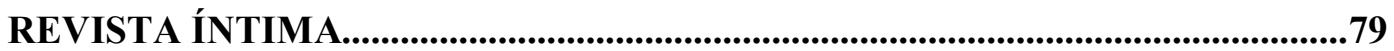

3.1. As famílias de presos como suspeitas: contribuições do Interacionismo

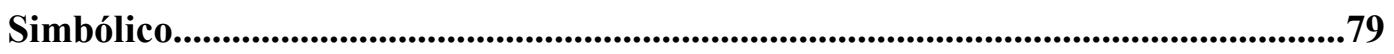

3.1.1. A Prisionização Secundária.................................................................8 81

3.1.1. Aspectos Teóricos da Prisionização Secundária..............................81

3.1.2. A Prisionização Secundária e as Famílias de Presos........................83

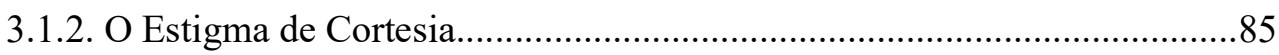

3.1.2.1. O Estigma na obra de Erving Goffman.......................................85

3.1.2.2. As Visitantes de Estabelecimentos Prisionais e o Estigma de

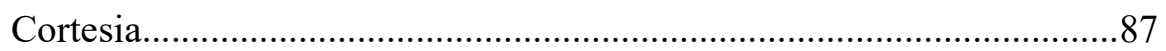

3.1.3. A Revista Íntima como Cerimônias de Degradação...................................93

3.2. O Interacionismo Simbólico como referencial teórico: problematizações da Criminologia Crítica...........................................................................................................96

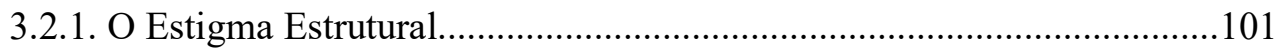

3.3. As Visitantes de Estabelecimentos Prisionais e a Questão de Gênero.................102

3.3.1. Breves Considerações sobre o uso da Categoria Social "Gênero" e a Teoria Feminista. .103

3.3.2. Gênero e Prisão: Relações entre a Teoria Feminista e a Criminologia......105

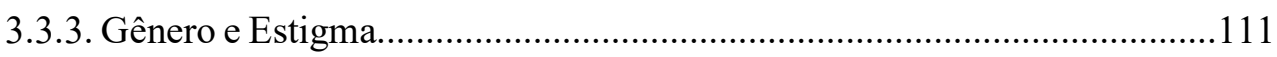

3.2.4. Revista Íntima: Violência Institucional de Gênero?..................................113 


\section{CAPÍtULO 4. AS ALTERAÇÕES NO PROCEDIMENTO DE REVISTA:}

POSICIONAMENTOS E DISPUTAS NAS ESFERAS DE PODER DO ESTADO BRASILEIRO.

4.1. O Poder Executivo: a atuação do Conselho Nacional de Política Criminal e Penitenciária.

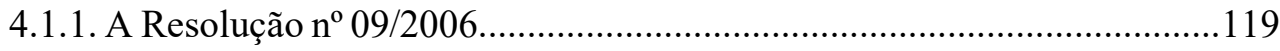

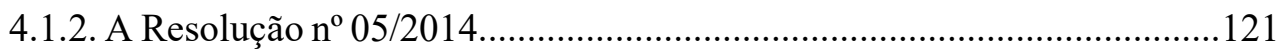

4.2. O Poder Judiciário...............................................................................................................124

4.2.1. Posicionamento dos Tribunais Superiores...............................................124

4.2.1.1. Considerações Metodológicas sobre a Pesquisa Jurisprudencial 125

4.2.1.2. Análise das Decisões do Superior Tribunal de Justiça sobre Revista Íntima

4.2.1.2.1. A Revista Íntima e os Princípios Constitucionais Penais na Jurisprudência do STJ.......................................................131

4.3. O Poder Legislativo.......................................................................................................134

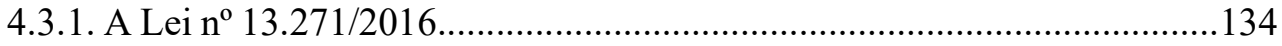

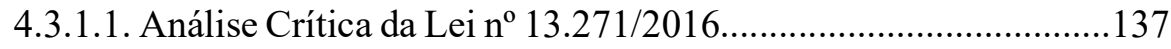

4.3.2. Outros Projetos de Lei Propostos sobre a Revista Íntima em Estabelecimentos Prisionais. 139

4.4. A Atuação da Sociedade Civil Organizada. .142

CAPÍtulo 5. A REVISTA ÍNTIMA NO ESTAdo DE SÃO PAULO E OS

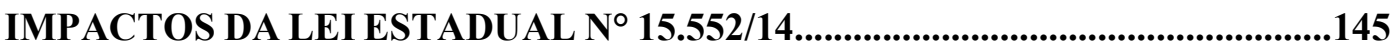

5.1. O Cenário Anterior à Mudança Legislativa...........................................................145

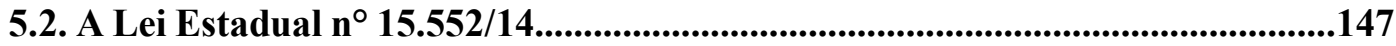

5.3. O (Peculiar) Caso da Cidade de Itirapina.............................................................149

5.4. O Cenário Atual da Revista no Estado de São Paulo..........................................156

CAPÍTULO 6. A VOZ DAS VISITAS: ENTRE CONSTATAÇÕES E QUESTIONAMENTOS..................................................................................................160

6.1. Considerações Metodológicas........................................................................................160

6.2. Passos Iniciais da Pesquisa.......................................................................................163 
6.2.1. A Escolha do Campo 163

6.2.2. A Pesquisa Exploratória. 166

6.2.3. A Elaboração dos Questionários Semiestruturados 168

6.3. Relatos das Filas de Visita e Análises Possíveis. 169

6.3.1. As Visitantes e a Pesquisadora: de quem se fala, com quem se fala... 169

6.3.2. Intranscendência da Pena e Dignidade Humana nas Formulações das Visitantes. 173

6.3.3. Ser familiar de preso: desconfiança e estigma. 176

6.3.4. Ser mulher e visitante: o impacto do gênero. 180 6.3.5. A mudança no procedimento da revista: uma conquista ou uma benção?

CONCLUSÕES. 189

REFERÊNCIAS 195

APÊNDICES. 207 APÊNDICE A - DECISÕES DO STJ SOBRE REVISTA ÍNTIMA

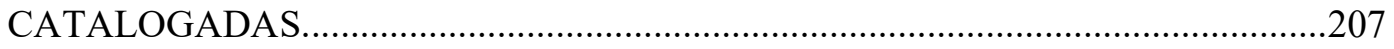

APÊNDICE B - QUESTIONÁRIO SEMIESTRUTURADO....................................215 APÊNDICE C - MODELO DE TERMO DE CONSENTIMENTO LIVRE E ESCLARECIDO 



\section{INTRODUÇÃO}

A chamada revista íntima ou revista vexatória ${ }^{1}$ é o procedimento de busca pessoal pelo qual a pessoa revistada deve se despir por completo e ter seu corpo inspecionado por terceiro supostamente apto a verificar a presença de objetos escondidos sob suas roupas ou no interior de alguma de suas cavidades corporais. Tal forma de busca pessoal foi por décadas o procedimento padrão para o controle realizado na entrada de familiares e amigos de presos que visitam os estabelecimentos prisionais brasileiros.

Apesar da aparente naturalidade com a qual a prática foi levada a cabo por longo período, ao final dos anos 2000 surgiram as primeiras reações ao procedimento, que apontavam ser ele causador de sérias violações de direitos fundamentais aos visitantes e pediam providências para a sua alteração. Após essas primeiras críticas, a questão da proibição da revista íntima em prisões foi alvo de inúmeros debates a nível nacional que tiveram como um de seus resultados mais emblemáticos a aprovação da lei $\mathrm{n}^{\mathrm{o}}$ 13.271/2016, que proibiu a prática em qualquer estabelecimento público ou privado no Brasil.

Pela amplitude da problemática, que permite diversas abordagens, a presente investigação tem como escopo principal compreender o percurso que levou às alterações ocorridas no procedimento de Revista ${ }^{2}$ nos estabelecimentos prisionais do país. Mais precisamente, busca-se verificar se como as críticas ao procedimento, que apontavam ser ele uma grave violação de direitos penais fundamentais, motivaram as iniciativas que levaram à edição de leis nacionais e estaduais que proibiram a prática.

Para tanto, o trabalho se divide em duas etapas. Na primeira parte, que compreende os três primeiros capítulos, objetiva-se entender o que é o a busca pessoal na modalidade íntima e como ela pode ser entendida pela ótica da Dogmática Penal, da Criminologia e dos aportes dos Estudos de Gênero.

\footnotetext{
${ }^{1}$ É comum o uso da denominação "revista vexatória" para a prática, como forma de denúncia das violações de direitos que a permeiam. Nesse momento inicial do trabalho, dar-se-á preferência para o termo "revista íntima" e após a discussão da pertinência do procedimento no decorrer da pesquisa será avaliado o uso do adjetivo "vexatória".

2 Como forma de evitar repetições sucessivas do termo "revista íntima", optou-se por empregar como sinônimo a palavra "Revista" (grafada com letra maiúscula). Portanto, quando se lê "Revista" ao longo desse trabalho, quer-se dizer revista na modalidade íntima, com desnudamento e inspeção de genitália, por sua vez, quando se diz "revista", se refere à busca pessoal em sua generalidade.
} 
O Capítulo 1 trata do procedimento de revista íntima, para isso, traz os conceitos mais amplos de busca e revista pessoal, segue para a descrição da revista íntima feita nos estabelecimentos prisionais brasileiros e é finalizado com o perfil dos visitantes de estabelecimentos prisionais que devem se submeter aos procedimentos descritos. Assim, cumpre o papel de delimitar do que e de quem trata o presente trabalho.

O Capítulo 2 contextualiza a importância dos princípios constitucionais penais, a partir da apresentação de possíveis contribuições do Direito Constitucional para o Direito Penal, notadamente das ferramentas da Teoria dos Princípios para a solução de controvérsias complexas. Em um segundo momento, trata-se de garantias penais constitucionais atinentes à revista íntima: a intranscendência da pena, a dignidade da pessoa humana e a legalidade, sendo feita a análise de seus contornos doutrinários e da incidência na questão da Revista. Ao final é proposta solução para o conflito entre as garantias constitucionais estudadas e o chamado "princípio da segurança", por vezes empregado como argumento para justificar a realização da revista íntima.

No Capítulo 3, dá-se seguimento ao estudo por meio das contribuições da Criminologia e da Teoria de Gênero sobre a questão.

Para tanto, na primeira parte do capítulo são apresentados os aportes fornecidos por teóricos do Interacionismo Simbólico, pioneiros em investigar os visitantes de prisões e a posição ocupada pelos familiares durante o cumprimento da pena. A partir disso, passa-se a um segundo momento, que tem como objetivo central entender como teóricos da Criminologia Crítica brasileira entendem hoje a situação dos visitantes. Ao final, são mobilizadas as contribuições teóricas com enfoque nas relações de gênero na prisão, que permitem um novo olhar sobre a situação dos visitantes e o questionamento a respeito de a revista íntima ser uma forma de Violência Institucional de Gênero.

Ao final desses três capítulos iniciais, dado o panorama teórico sobre a questão, é constatado se a revista íntima é uma prática violadora de direitos penais fundamentais, como as violações de direitos ocorrem no cotidiano daqueles que visitam e como as visitantes mulheres participam da problemática de maneira própria.

A partir dessas constatações, inicia-se a segunda parte do trabalho, na qual se analisa como as críticas teóricas se mostram na realidade nacional. Para tanto, parte-se das iniciativas de mudança de impacto nacional, analisa-se o processo verificado no Estado de São Paulo e chega-se à visão de visitantes de dois estabelecimentos prisionais sobre as questões debatidas durante esse trabalho. 
Assim sendo, no Capítulo 4 estuda-se a forma como o Estado Brasileiro lidou com a questão da Revista em suas diversas instâncias de poder. Inicia-se com as primeiras iniciativas, encontradas no Poder Executivo, por meio da regulamentação dos procedimentos de Revista pelo Conselho Nacional de Política Criminal e Penitenciária (CNPCP). No tópico seguinte, observa-se a atuação do Poder Judiciário, a partir de pesquisa empírica sobre a jurisprudência dos Tribunais Superiores em casos nos quais a revista íntima é tratada. Por fim, no âmbito do Poder Executivo, são estudados os projetos de lei em trâmite que concernem o tema e traz-se à análise a lei $n^{\circ} 13.271 / 2016$, que tornou proibida a revista íntima em território nacional.

Ao final deste quarto capítulo, também é descrita a forma como a Sociedade Civil organizada atuou nessas diversas esferas estatais, com destaque à Campanha contra a Revista Vexatória da Rede de Justiça Criminal iniciada no ano de 2014.

No Capítulo 5 é analisada a forma como foi abolida a revista íntima no Estado de São Paulo. Para isso, são descritos os debates legislativos que levaram à edição da lei estadual $\mathrm{n}^{0} 15.552 / 14$, as potenciais mudanças que ela permitirá nas prisões paulistas e as possíveis falhas que apresenta à luz dos princípios constitucionais penais estudados no Capítulo 2. Ao final, para é proposto um breve estudo de caso da situação vivida na Penitenciária de Itirapina no ano de 2015, onde, após a sanção da lei estadual mencionada, instaurou-se conflito em torno da aplicação imediata da suspensão da revista. Trata-se de cenário interessante para análise por ter envolvido distintos posicionamentos sobre à questão, que partiram de visitantes, agentes penitenciários, a Defensoria Pública, a Secretaria de Administração Penitenciária e o Poder Judiciário

Finalmente, o Capítulo 6 traz os relatos recolhidos em campo durante a pesquisa empírica desenvolvida com visitantes de estabelecimentos prisionais da grande São Paulo. Nas diversas conversas realizadas nas filas em que se aguarda aos finais de semana, os visitantes puderam trazer sua visão sobre diversos pontos centrais para esse trabalho e, assim, demonstrar como as contribuições teóricas da Dogmática Penal, da Criminologia estão presentes em suas falas, além de relatar como enxergaram e vivenciaram o processo de instalação de Escâneres Corporais que substituíram a revista na modalidade íntima no Estado de São Paulo.

Ao final do percurso proposto, será possível entender se as iniciativas de alteração dos procedimentos de revista nas unidades prisionais do país foram motivadas pelas críticas oriundas dos princípios constitucionais penais e avaliar o quão próximas estão as contribuições teóricas da Dogmática Penal e da Criminologia, as motivações 
políticas que levaram à proibição legal da Revista e a visão dos visitantes sobre o processo de mudança. 


\section{CONCLUSÃO}

O procedimento de revista íntima, ao qual foram submetidas visitantes de estabelecimentos prisionais durante décadas (e que ainda é prática corriqueira em inúmeras prisões brasileiras), é uma prática contrária ao conjunto de princípios penais previstos constitucionalmente.

Tal conclusão foi possível com a análise do conteúdo das garantias constitucionais da Dignidade Humana e da Intranscendência da Pena. A partir delas, entendeu-se que a Revista é condenável por afetar as visitantes de maneira danosa e indelével, além de representar a extensão de consequências negativas da prisão para indivíduos que não poderiam sofrer efeitos da condenação criminal.

Apesar dessas garantias, verificou-se que os posicionamentos favoráveis à manutenção da revista íntima como forma primordial de impedir a entrada de objetos proibidos em estabelecimentos prisionais se baseavam na suposta prevalência do chamado "Princípio da Segurança" em face dos demais estudados. Para solucionar esse conflito foram úteis as ferramentas oferecidas pela Teoria dos Princípios, que permitiram demonstrar a faceta violadora do procedimento objeto dessa dissertação para além de uma mera argumentação retórica.

Nas diversas etapas da regra da Proporcionalidade empregadas para resolução do confronto entre os princípios penais estudados e a segurança dos estabelecimentos prisionais, foi descrito o raciocínio seguido e feita a avaliação de todas as alternativas conhecidas à revista íntima. Após esse percurso, foi possível concluir que não é constitucionalmente adequada a prevalência da segurança em detrimento do arcabouço principiológico que protege as visitantes e que a Revista é uma prática vexatória.

Além do debate sobre princípios, foi apresentada a garantia da Legalidade, neste trabalho classificada como regra. Pelo seu campo de incidência, verificou-se que a forma inicial de regulamentação do procedimento de revista íntima, presente em Portarias Estaduais e em Resoluções do Conselho Nacional de Política Criminal e Penitenciária (CNPCP), não atendia à exigência de clareza e precisão da normativa penal derivada da legalidade. Isso porque, ainda que a Revista estivesse prevista em normas de direito penitenciário, sua realização com base na ideia de que havia "fundada suspeita" em relação às visitantes era contrária à Legalidade. 
Ao tratar as garantias constitucionais penais dessa forma, buscou-se demonstrar como elas podem ser mais que meras enunciações esvaziadas de conteúdo normativo, limitadas ao campo teórico, de modo que pudessem ser verdadeiramente aplicadas para resolução de questões complexas. Isso foi possível ao serem trazidos os subsídios do Direito Constitucional para a Dogmática Penal, evidenciando a indissociável relação entre os dois campos jurídicos.

Se por um lado a Dogmática apresentou as ferramentas para fosse vencido um impasse aparentemente invencível entre garantias constitucionais, as análises sociológicas sobre a situação das famílias de pessoas presas demonstraram, sob outra ótica, a necessidade do fim da revista vexatória.

Os aportes da Criminologia foram centrais para explicar o porquê de as visitantes de presos serem o único grupo, dentre todos aqueles que circulam pela prisão, que deveria se submeter à revista íntima. A justificativa encontrada na esparsa normativa sobre a questão baseava-se na previsão de que a revista seria executada em situações de "fundada suspeita".

Esse tratamento diferenciado destinado às visitantes, embasado na suposição de que seriam um grupo naturalmente perigoso, pôde ser explicado em um primeiro momento por meio da contribuição de teóricos inseridos na tradição do Interacionismo Simbólico. Tais análises tinham enfoque nas relações interpessoais vivenciadas pelos familiares de presos, fundadas na prisionização e no estigma, e produziam uma identidade virtual degradada das visitantes, que seriam uma ameaça à segurança do ambiente carcerário.

As respostas fornecidas pelo Interacionismo Simbólico foram colocadas à prova com as críticas oriundas da Criminologia Crítica, que indicavam a necessidade de um olhar mais amplo sobre as visitantes e de um enfoque maior que suas interações intersubjetivas cotidianas. Essas propostas críticas demonstraram que não é o envolvimento com a prisão que torna as visitantes estigmatizadas e degrada sua identidade, mas o fato de elas e de seus familiares pertencerem ao extrato social mais marginalizado, que é visto como suspeito mesmo antes de qualquer condenação criminal e por isso merecedor de uma proteção de direitos mais débil na visão hegemônica.

Tais apontamentos do Interacionismo Simbólico e da Criminologia Crítica, apesar de divergirem em relação a seus pressupostos teóricos, ao final, trouxeram conclusões que caminhavam juntas para demonstrar como se tornou justificável conferir 
às visitantes das prisões brasileiras tratamento contrário às garantias constitucionais que deveriam lhe proteger de situações vexatórias.

As formas degradantes de tratamento recebidas pelas visitantes, explicadas pela Criminologia, ganharam contornos mais claros quando o marcador social do gênero foi trazido no terceiro capítulo. O fato de haver uma maioria de mulheres visitantes demonstrou como a esfera do cuidado ainda recai sobre a figura feminina e como o Cárcere é um universo apartado das relações de poder baseadas no gênero que permeiam toda a sociedade. O gênero foi compreendido, desta forma, como mais um fator que contribui para a vulnerabilidade da proteção de direitos fundamentais conferida às visitantes, que vivenciam formas potencializadas de estigmatização por serem mulheres.

A assimetria de poder baseada no gênero apresenta desdobramentos nas relações verificadas entre visitantes mulheres e seus parentes homens presos, tendo como seu ápice a criação de um ideal feminino que combina a resistência em enfrentar os obstáculos impostos pelo Sistema Prisional e a submissão à figura masculina.

Em relação à revista vexatória propriamente, os aportes da Teoria de Gênero permitiram compreende-la como uma forma de Violência Institucional de Gênero, pois afeta mulheres de maneira particularmente nociva, em razão da relação que têm com a nudez e exposição de seu corpo, bem como com o fato notório de que a maioria das visitantes de prisões é mulher.

Do estudo da situação das famílias de presos sob a perspectiva da Criminologia, posteriormente congregado ao impacto do gênero na análise, foi possível depreender como as descritas violações de direitos penais fundamentais concernentes à Revista puderam ser naturalizadas como procedimentos imutáveis e necessários por tantos anos. Tal fato denota que, apesar da Dogmática fornecer os instrumentos teóricos para a garantia e efetivação de direitos fundamentais penais, suas soluções não se traduzem automaticamente em decisões das instâncias de poder cuja atuação tem respaldo no Sistema Carcerário.

Nessa linha, os diversos dos debates travados no Conselho Nacional de Política Criminal e Penitenciária reconheceram o conflito entre princípios penais presente na questão da Revista, mas permaneceram paralisados frente a ele, como se não houvesse solução viável para o impasse que se apresentava. Assim, diversas das saídas propostas não passavam de formas de mascarar a manutenção da revista íntima, com alternativas como a regulamentação da prática para sua realização somente quando houvesse a "fundada suspeita" já criticada sob diversas perspectivas. 
No Poder Judiciário, notadamente nos Tribunais Superiores, também não se observou o uso das ferramentas teóricas descritas nas decisões dos Ministros acerca da pertinência constitucional da revista vexatória. Como se verificou, não houve menção ao uso da proporcionalidade como instrumento de avaliação da Revista ou de suas alternativas e não foram feitas considerações extensas sobre os impactos dela às visitantes. Em suma, não houve nessa esfera decisória uma crítica ao procedimento estudado.

De modo um pouco distinto se deram os debates verificados no Legislativo Federal, que congregaram diversos posicionamentos sobre a questão. Neles, foi possível notar a presença dos princípios constitucionais penais estudados, além de elementos próprios da análise sociológica, como o impacto que o gênero nas questões atinentes à Revista.

A aprovação da lei $n^{\circ} 13.271 / 2016$, que proibiu formalmente qualquer forma de revista íntima no Brasil, foi permeada pela mobilização de diversas organizações da Sociedade Civil voltadas à promoção de Direitos Humanos. Dentre as iniciativas, destacou-se a atuação de Rede de Justiça Criminal, que congregou ONGs e a Defensoria Pública do Estado de São Paulo e permitiu trazer às instâncias decisórias, notadamente ao Legislativo Federal, a argumentação jurídica apta a justificar a necessidade de se proibir a revista íntima e de se buscar alternativas não violadoras da dignidade pessoal das visitantes de prisões no Brasil.

Assim, notou-se que a mobilização política da Sociedade Civil organizada foi um veículo fundamental para trazer algumas das considerações teóricas apresentadas na primeira parte desse trabalho até os espaços decisórios em que alguma mudança concreta na situação das visitantes poderia ser atingida. Em outras palavras, percebeu-se que, para garantir direitos fundamentais na seara penal, é necessário que a produção teórica se atente a demandas políticas relevantes e que a sociedade civil organizada encontre na Dogmática as ferramentas necessárias para debater questões complexas, afirmando posicionamentos garantistas de maneira embasada.

A forma como se deu a proibição da Revista no Estado de São Paulo também reforça essa conclusão. Como visto, mesmo com a edição da lei estadual $n^{\circ}$ 15.552/14, houve prolongada resistência do Governo do Estado em tornar realidade as previsões legais e tomar as medidas necessárias para a instalação dos aparelhos que substituiriam a busca pessoal com desnudamento. A licitação dos Escâneres Corporais de forma integrada para todas as penitenciárias e centros de detenção provisória paulistas ocorreu 
apenas após sucessivas ações judiciais promovidas pela Defensoria Pública em conjunto a outras organizações voltadas à promoção de Direitos Humanos.

Apesar dos inegáveis avanços da normativa sobre a questão que proibiram Revista em todos os estabelecimentos do país, sejam eles públicos ou privados, e possibilitaram mudanças práticas, como no caso do Estado de São Paulo, que no ano de 2018 conta com escâneres corporais instalados em todos seus estabelecimentos prisionais, deve-se observar esse cenário aparentemente vitorioso com cautela.

Nacionalmente, mesmo com todas as inovações legais apresentadas, há diversas localidades que ainda tem a revista vexatória como procedimento padrão na entrada de visitantes. Fato se agrava ao ser constatado que a campanha impulsionadora das normativas nacional e estaduais a partir do ano de 2015 não se manteve ativa da mesma maneira após as conquistas no âmbito legislativo.

Por sua vez, na vivência cotidiana das famílias, apresentada no capítulo final dessa dissertação, restou evidente o afastamento das mulheres que enfrentam a revista íntima do processo político e jurídico resultante na abolição da prática. Tal constatação não significou uma ausência de consciência das visitantes a respeito da importância da mudança verificada ou das consequências negativas que a revista vexatória apresentou, mas indicou que, para elas, as suas reivindicações não foram o que motivou as mudanças na forma como se revistava as visitantes.

Por conseguinte, pelo fato de todo histórico da mudança legislativa apresentado e as reivindicações políticas feitas não terem sido conhecidos entre as visitantes, o fim da revista íntima se tornou algo como uma dádiva concedida sem grandes explicações, medida praticamente divina, "uma benção".

Essa constatação mostrou que as iniciativas para reivindicação de garantias fundamentais no Sistema Penal devem ter embasamento na produção teórica fornecida pela Dogmática e pela Criminologia, ao mesmo tempo em que precisam considerar a visão dos sujeitos que vivenciam a prisão, seja no seu interior ou em trânsito por seus muros. A importância da voz das visitantes nesse trabalho serviu para demonstrar como as alterações legislativas e mudanças práticas relevantes também precisam ser compreendidas pelas pessoas por elas afetadas, pois assim poderiam perceber que são titulares de direitos e não recebedoras de benesses.

As conclusões traçadas ao longo do trabalho também apontaram para o fato de que a proibição da revista vexatória não deve ser vista de maneira simplista, como uma conquista que tornou o sistema prisional brasileiro mais próximo do que pode ser 
entendido como "prisão ideal". Ao contrário, as justificativas que embasaram por décadas a revista vexatória de forma reiterada e que posicionavam as famílias de presos como pessoas suspeitas e merecedoras de menor proteção jurídica ainda permanecem, pois estão fundadas nas formas de violência imanentes à estrutura econômica e social e ao funcionamento seletivo da pena de prisão.

Portanto, ainda que fim da revista vexatória tenha tornado os dias de visita de estabelecimentos prisionais no Brasil menos dolorosos, ele não retirou das visitantes as implicações que acompanham o fato de tais mulheres se tornarem sujeitos indissociáveis de seus parentes presos com o cumprimento da pena e com isso sofrerem consequências danosas.

Ao final, a reflexão que permanece é o quanto é possível compatibilizar os Princípios Constitucionais Penais em sua força normativa com a própria prisão. Nos moldes em que o cárcere como Instituição existe e é verificado na realidade brasileira é praticamente impossível que a pena não ultrapasse a pessoa do condenado ou que a dignidade das visitantes não seja colocada à prova. Reconhecer isso não significa invalidar por completo a função da Dogmática Penal ou da Teoria dos Princípios, mas orientar sua aplicação, com coerência teórica, para ser uma ferramenta apta a limitar ao máximo os efeitos nocivos da prisão, sem que a legitime como forma primordial de punição. 


\section{REFERÊNCIAS}

AGUIAR, Janaína. Violência institucional em maternidades públicas: hostilidade ao invés de acolhimento como uma questão de gênero. 2010. Tese (Doutorado em Medicina Preventiva) - Faculdade de Medicina, Universidade de São Paulo, 2010.

ALEXY, Robert. Teoria dos Direitos Fundamentais. Trad. Virgílio Afonso da Silva. São Paulo: Malheiros, 2008.

ALMEIDA, Roberto. Estudo de caso: foco temático e diversidade metodológica in Métodos de pesquisa em Ciências Sociais: Bloco Qualitativo. Sesc São Paulo/CEBRAP: São Paulo, 2016.

ALMEIDA, Silvana de. Dignidade humana e filosofia hegeliana. In Anais do seminário dos estudantes de pós-graduação em filosofia da UFSCar. São Carlos, n. 10, set. 2014.

ALMEIDA, Telma; BRITO, Marcelo; ALMEIDA, Douglas. A Revista Íntima Feminina no Sistema Penitenciário Brasileiro à Luz do Princípio da Dignidade da Pessoa Humana. Anais do IV Congresso em Desenvolvimento Social, n. 4, mai. 2014.

ALVAREZ, Marcos César; SALLA, Fernando; DIAS, Camila. Das Comissões de Solidariedade ao Primeiro Comando da Capital em São Paulo in Tempo Social, São Paulo, v. 25, n. 1, p. 61-82, 2013.

ALVES, Jamil. Princípio da personalidade da pena e execução penal. Revista dos Tribunais, São Paulo v. 99, n. 899, p. 431-454, set., 2010.

ARAUJO, Fernanda de. A Teoria Criminológica do Labelling Approach e As Medidas Socioeducativas. 2010. Dissertação (Mestrado em Direito Penal, Medicina Forense e Criminologia) - Faculdade de Direito, Universidade de São Paulo. São Paulo, 2010.

BARATTA, Alessandro. Criminología Crítica e crítica del Derecho Penal: Introducción a la Sociología jurídico-penal. Buenos Aires: Siglo Veintiuno Editores Argentina, 2004. 
BARCINSKI, Mariana et al. Guerreiras do cárcere: uma rede virtual de apoio aos familiares de pessoas privadas de liberdade. Temas psicol., Ribeirão Preto, v. 22, n. 4, dez. 2014.

BARCINSKI, Mariana et al . O Marianismo e a vitimização de mulheres encarceradas: formas alternativas de exercício do poder feminino. Ex aequo, Vila Franca de Xira, n. 28, p. 87-100, 2013.

BARROSO, Luís Roberto (Org.). A nova interpretação constitucional: ponderação, direitos fundamentais e relações privadas. 3. ed. Rio de Janeiro: Renovar, 2008.

BARROSO, Luís. Neoconstitucionalismo e Constitucionalização do Direito (O triunfo tardio do direito constitucional no Brasil). Revista de Direito Administrativo, Rio de Janeiro, n. 240, abr./jun., 2005.

BEAUVOIR, Simone. O Segundo Sexo: A Experiência Vivida. Tradução de Sérgio Milliet. $2^{\mathrm{a}}$ Edição. São Paulo: Difusão Européia do Livro, 1967.

BELO, Warley. Jurisprudência organizada sobre os princípios do Direito Penal. Florianópolis: Bookess, 2012.

BITENCOURT, Cezar. Tratado de Direito Penal: parte geral. $14^{\mathrm{a}}$ ed. São Paulo: Saraiva, 2009.

BITTAR, Eduardo. Ética, Cidadania e Constituição: O Direito à Dignidade e à Condição Humana. Revista Brasileira de Direito Constitucional, n. 8, jul./dez., 2006.

BRAGA, Ana Gabriela. A Identidade do Preso e as Leis Do Cárcere. 2008. Dissertação (Mestrado em Direito Penal, Medicina Forense e Criminologia) - Faculdade de Direito, Universidade de São Paulo, São Paulo, 2008

BRAGA, Ana Gabriela. Reintegração Social: discursos e práticas na prisão-um estudo comparado. 2000. Tese (Doutorado em Direito Penal, Medicina Forense e Criminologia) - Faculdade de Direito, Universidade de São Paulo, São Paulo, 2012

BRASIL. MINISTÉRIO DA JUSTIÇA. Levantamento Nacional de Informações Penitenciárias, 2014. 
BRASIL. Ministério da Saúde. Secretaria de Políticas de Saúde. Violência intrafamiliar: orientação para prática em serviço, 2001.

BRITO, Alexis de. Execução penal. 3. ed. São Paulo: Revista dos Tribunais, 2013.

BUORO, Andréa. Negociando a dignidade humana. 1998. Dissertação (Mestrado em Antropologia Social) - Faculdade de Filosofia, Letras e Ciências Humanas, Universidade de São Paulo, São Paulo, 1998.

BUTLER, Judith. Problemas de Gênero. $13^{\mathrm{a}}$ Edição. Rio de Janeiro: Civilização Brasileira, 2017

CERNEKA, Heidi Ann. Homens Que Menstruam: Considerações Acerca Do Sistema Prisional Às Especificidades Da Mulher. Veredas do Direito, Belo Horizonte, v. 6, n. 11, 2009.

CHAUÍ, Marilena Participando do debate sobre mulher e violência. In: Chauí M, Cardoso R, Paoli MC, organizadores. Perspectivas Antropológicas da Mulher. Rio de Janeiro: Zahar. 1985.

CHIES, Luiz Antônio Bogo. A capitalização do tempo social na prisão: a remição no contexto das lutas de temporalização na pena privativa de liberdade. São Paulo: IBCCRIM - Instituto Brasileiro de Ciências Criminais, 2008.

CLEMMER, Donald. Observations on Imprisonment as a Source of Criminality. Journal of Criminal Law and Criminology, Chicago, v. 41, 1950.

CLEMMER, Donald. The Prison Community. New York: Holt, Rinehart and Winston, 1940.

COMISSÃO INTERAMERICANA DE DIREITOS HUMANOS. Caso n ${ }^{0} 10.506$ Argentina vs. X e Y. Decisão em: 15 de outubro de 1996. Disponível em: https://www.cidh.oas.org/annualrep/96span/Argentina10506.htm\#_ftn1.

COMPARATO, Fábio Konder. A afirmação histórica dos direitos humanos. 1. ${ }^{\mathrm{a}}$ ed. São Paulo: Saraiva, 1999. 
CORREA, Marcus. O Conflito de Princípios e as Falácias da Liberdade. Revista Brasileira de Direito Constitucional, São Paulo, n. 17, jan./jun., 2011.

CORREIA, Marcus. O Postulado da Razoabilidade e o Direito do Trabalho. Revista da Faculdade de Direito da Universidade de São Paulo, v. 101, jan./dez, 2006.

COSTA, Helena da. A Dignidade Humana: teorias de prevenção geral positiva. São Paulo: Revista dos Tribunais, 2008.

COYLE, Andrew. Administração Penitenciária: Uma Abordagem de Direitos Humanos - Manual para servidores penitenciários. Londres: International Centre for Prison Studies, 2002.

CURTIN, Deane; LITKE, Robert. Institutional Violence. Amsterdam: Rodolpi, 1999.

DEFENSORIA PÚBLICA DO ESTADO DE SÃO PAULO. Núcleo de Situação Carcerária. Dados sobre a apreensão de objetos ilícitos (armas, drogas e celulares) em unidades prisionais e análise da eficácia do procedimento de revista íntima em visitantes de unidades prisionais, 2014.

DOTTI, René. Curso de Direito Penal: parte geral. 4. ed. São Paulo: Revista dos Tribunais, 2012.

DUTRA, Yuri Frederico. A inconstitucionalidade da Revista Íntima realizada em familiares de presos, a segurança prisional e o princípio da dignidade da pessoa humana. Novos Estudos Jurídicos, Itajaí, v. 13, n. 2, p.93-104, jul./dez, 2008.

DUTRA, Yuri Frederico. Como se estivesse morrendo: a prisão e a revista íntima em familiares de reclusos em Florianópolis. 2008. Dissertação (Mestrado em Direito) Faculdade de Direito, Universidade Federal de Santa Catarina, Florianópolis.

FAVRET-SAADA, Jeanne. Ser afetado. Cadernos de Campo, v.13, n.13, 2005.

FERRAJOLI, Luigi. Direito e razão: teoria do garantismo penal. 3. ed. rev. São Paulo: Editora Revista dos Tribunais, 2002. 
FERRÉ OLIVÉ, Juan Carlos et al. Direito Penal brasileiro; parte geral: princípios fundamentais e sistema. São Paulo: Revista dos Tribunais, 2011.

FERREIRA, Rafael. (A)Crítica Recepção das Teses Alexyanas: o locus da discricionariedade judicial em terrae brasilis. Direitos Fundamentais \& Justiça, Porto Alegre, ano 7, no 25, p. 87-114, out/dez. 2013.

FERRELL, Jeff. Criminological Verstehen: inside the immediacy of crime In Etnography at the Edge: Crime Deviance and Field Research. Boston: Northeastern University Press, 1998.

FERRELL, Jeff; HAMM, Mark. True Confessions: Crime Deviance and Field Research. In Etnography at the Edge: Crime Deviance and Field Research. Boston: Northeastern University Press, 1998.

FEUERBACH. Revision der Grundsätze und Grundbegriffe des positiven peinlichen Rechts. Aalen: Scientia Verlag, 1966.

FRASER, Nancy. Da redistribuição ao reconhecimento? Dilemas da justiça numa era pós-socialista. Cadernos de Campo, 2006, nº 14-15, p. 232.

FRAZIER, Ian. Scratch And Sniff. New Yorker, Nova Iorque. 19 out. 2009. Disponível em: http://www.newyorker.com/magazine/2009/10/19/scratch-and-sniff.

GARFINKEL, Harold. Conditions of Successful Degradation Ceremonies. American Journal of Sociology, vol. 61, $\mathrm{n}^{\circ}$. 5, mar, 1956.

GODOI, Rafael. Fluxos em cadeia: as prisões em São Paulo na virada dos tempos. 2015. Tese (Doutorado em Sociologia) - Faculdade de Filosofia, Letras e Ciências Humanas, Universidade de São Paulo, São Paulo, 2015

GODOI, Rafael. Para uma reflexão sobre os efeitos sociais do encarceramento. Revista Brasileira de Segurança Pública. São Paulo, ano 5, ed 8. fev./mar., 2011.

GOFFMAN, Erving. Estigma: notas sobre a manipulação da identidade deteriorada. Tradução de Márcia Bandeira de Mello Leite Nunes. 4. ed. Rio de Janeiro: LCT, 1988. 
GOtTfRedson, Michael; Hirschi, Travis. A general theory of crime. Stanford: Stanford University Press, 1990.

HANNEN, Stacey. Marked by Association: Stigma, Marginalization, Gender and The Families of Male Prisioners in Canada. 2008. Tese (Doutorado em Sociologia) Carleton University, Otawwa, Ontario.

HARDING, S. Feminism \& methodology. Bloomington e Indianapolis: Indiana University Press Open University Press, 1987.

HEGEL, Georg Wilhelm. Filosofia do Direito. Tradução: Paulo Meneses. et al. São Leopoldo: Ed. UNISSINOS, 2010.

HELPES, Sintia. Vidas em Jogo: um estudo sobre mulheres envolvidas com tráfico de drogas. São Paulo: IBCCRIM, 2014.

HONNETH, Axel. Luta por reconhecimento: a gramática moral dos conflitos sociais. Trad. de Luiz Repa. São Paulo: Editora 34, 2003.

IBCCRIM. Revista vexatória: o estupro institucionalizado. Boletim do IBCCRIM, São Paulo, v. 23, n. 267, p.1, fev. 2015.

IMMANUEL, Kant. Grundlegung zur Metaphysik der Sitten. Stuttgat: Reclams Universal-Bibliothek, 1961.

JAKOBS, Günther et al. Tratado de Direito Penal: teoria do injusto penal e culpabilidade. Belo Horizonte: Del Rey, 2009.

JAKOBS, Gunther. Derecho Penal Parte General: Fundamentos y Teoría de la imputación. Madrid: Marcial Pons, 1995.

JESCHECK, Hans-Heinrich. Tratado de derecho penal: parte general. 4. ed. Granada: Comares, 1993.

JUNQUEIRA, Gustavo; FULLER, Paulo Henrique Aranda. Legislação penal especial. 6. ed. São Paulo: Saraiva, 2009. 
LAGO, Natália. Mulher de preso nunca está sozinha: gênero e violência nas visitas à prisão in ARAC $\hat{\mathbf{E}}$ - Direitos Humanos em Revista, ano 4, n. 5, fev., 2017.

LASCANO, Carlos Julio Org. Derecho penal: parte general, libro de estudio. Córdoba: Advocatus, 2005.

LEAL, César Barros. Execução penal na América Latina à luz dos direitos humanos: viagem pelos caminhos da dor. Curitiba: Juruá, 2012.

LÉLLIS, Leonardo e GRILLO, Brenno. Lei proíbe revista íntima em mulheres e reabre debate sobre segurança. Consultor Jurídico, São Paulo.

LIMA, Jacqueline de. Mulher fiel: as famílias das mulheres dos presos relacionados ao Primeiro Comando da Capital. 2013. Dissertação (Mestrado em Antropologia Social) - Universidade Federal de São Carlos, São Carlos, 2013.

LOPES Jr. Aury. Direito Processual Penal. 11ª ed. São Paulo: Saraiva, 2014.

LOPES JR., Aury. Introdução Crítica ao Processo Penal: Fundamentos da Instrumentalidade Garantista. Rio de Janeiro, Editora Lumen Juris, p. 34.

LUISI, Luiz. Os princípios constitucionais penais. Porto Alegre: Sergio Antonio Fabris, 1991.

MARIATH, Carlos Roberto. Limites da Revista Corporal no âmbito do Sistema Penitenciário. Revista Jus Navigandi, Teresina, ano 13, n. 1761, 27 abr., 2008.

MATTLEY, Christine. (Dis)Courtesy Stigma - Fieldwork among Phone Fantasy Workers. In Etnography at the Edge: Crime Deviance and Field Research. Boston: Northeastern University Press, 1998.

MAY, Tim. Pesquisa Social: questões, métodos e processos. Tradução de Carlos Alberto Silveira Netto Soares. 3.ed. Porto Alegre: Artmed, 2004.

MISSE, Michel. Malandros, Marginais e Vagabundos \& a acumulação social da violência no Rio de Janeiro. 1999. Tese (Doutorado em Sociologia) - Departamento de Sociologia do IUPERJ, Rio de Janeiro, 1999. 
MORAES Marcia, TSALLIS Alexandra. Contar histórias, povoar o mundo: a escrita acadêmica e o feminino na ciência. Rev. Polis e Psique, Porto Alegre, n. 6, 2016.

MOURA, Maria Fernanda. O princípio da intranscendência da pena: o impacto na vida dos familiares. Monografia (Graduação em Direito) - Faculdade de Direito da Universidade Federal do Estado do Rio de Janeiro, Rio de Janeiro, 2012.

MOURA, Maria Jurema. Mulher, tráfico de drogas e prisão. Fortaleza: Eduece, 2012.

NASSARO, Adilson Luís Franco. A busca pessoal e suas classificações. A força policial: órgão de informação e doutrina da instituição policial militar, São Paulo, v. 51, n. 51, p.57-73, jul./set, 2006.

NUVOLOnE, Pietro. O sistema do Direito Penal. São Paulo: Revista dos Tribunais, 1981.

OKIN, Susan. Justice, Gender and The Family. New York: Basic Books, 1989.

PACHUKANIS, Evgeny Bronislavovitch. Teoria geral do direito e marxismo. São Paulo: Acadêmica, 1988.

PALAZZO, Francesco Carlo; SANTOS, Gérson Pereira dos (trad.). Valores constitucionais e Direito Penal: um estudo comparado. Porto Alegre: Sergio Antonio Fabris, 1989.

PALMA; FEFERBAUM; PINHEIRO, V. M. Meu trabalho precisa de jurisprudência? Metodologia jurídica: um roteiro prático para trabalhos de conclusão de curso. São Paulo: Saraiva, 2012.

PAPP, Gábor. Prisonization And/Or Criminalization?. Hungarian Statistical Review, n. 16, 2012.

PATON, Herbert. The Categorical Imperative: A study in Kant's Moral Philosophy. Londres: Hutchinson's University Library, 1946.

PIERIANGELI, José; ZAFFARONI, Eugenio. Manual de Direito Penal Brasileiro: Parte Geral. 9 ed. São Paulo: Revista dos Tribunais, 2011. 
PITOMBO, Cleunice. Da Busca e da Apreensão no Processo Penal. $2^{\text {a }}$ ed. São Paulo: RT, 2005.

POLO, Giovana. Busca e apreensão pessoal e prova ilícita. Boletim IBCCRIM, São Paulo, v. 8, n. 92, p.9, jul, 2000.

PRADO, Fabiana. A ponderação de interesses em matéria de prova no processo penal. São Paulo: IBCCRIM, 2006.

PRADO, Luiz Regis. Tratado de Direito Penal brasileiro parte geral: introdução, história, lei penal, princípios e bem jurídico. São Paulo: Revista dos Tribunais, 2014.

RIEZU, Antonio. El principio constitucional de responsabilidad personal por el hecho proprio. Manifestaciones cuantitativas. Anuario de derecho penal y ciencias penales, Madrid, v. 62, p. 211-252, jan./dez, 2009.

ROSA, Bruna de. A Revista Íntima em Crianças e Adolescentes nos Estabelecimentos Prisionais Catarinenses Frente à Doutrina da Proteção Integral e do Princípio da Dignidade da Pessoa Humana. 2014. Monografia de Conclusão de Curso (Graduação em Direito) - Faculdade de Direito, Universidade do Extremo Sul Catarinense, Criciúma, 2014.

SANTOS, Juarez Cirino dos. Manual de Direito Penal: parte geral. 6 . ed. Florianópolis: Conceito, 2014.

SANTOS, Thiago Pedro Pagliuca dos. O princípio da ofensividade como complemento necessário à regra da legalidade penal no Estado Democrático de Direito. 2014. Dissertação (Mestrado em Direito Penal) - Faculdade de Direito, Universidade de São Paulo, São Paulo, 2014.

SARLET, Ingo Wolfgang. Dignidade (da pessoa) humana e direitos fundamentais na Constituição Federal de 1988. Porto Alegre: Livraria do Advogado, 2010.

SARLET, Ingo. As Dimensões da Dignidade da Pessoa Humana. Revista Brasileira de Direito Constitucional, n. 9, jan./jun, 2007. 
SCHWARTZ, Barry. Waiting, Exchange, and Power: The Distribution of Time in Social Systems. American Journal of Sociology, v. 79, n. 4, jan., 1974.

SCOTT, Joan. Gênero: uma categoria útil de análise histórica. Tradução de Guacira Lopes Louro. Educação \& Realidade. Porto Alegre, v. 20, nº 2, 1995

SHECAIRA, Sérgio Salomão. Criminologia. 2. ed. São Paulo: Revista dos Tribunais, 2008 .

SILVA SÁNCHEZ, Jesús María. Responsabilidad individual o responsabilidad social en el delito. Revista peruana de ciencias penales, Lima, 7/8, n. 12, p.193-198, 2002.

SILVA, Ivan da. Das bases constitucionais do Direito Penal. Revista de Informação Legislativa. Brasília a. 39 n. 156 out./dez, 2002.

SILVA, José Afonso da. Curso de direito constitucional positivo. 24. ed. rev e atual. São Paulo: Malheiros, 2005.

SILVA, Luís Virgílio Afonso da. O proporcional e o razoável. Revista dos Tribunais, São Paulo, ano 91, n. 798, p. 23-50, abr. 2002.

SILVA, Virgílio Afonso da. Direitos fundamentais: conteúdo essencial, restrições e eficácia. São Paulo: Malheiros, 2009.

SILVA, Virgílio Afonso da. Princípios e regras: mitos e equívocos acerca de uma distinção. Revista Latino-Americana de Estudos Constitucionais, Belo Horizonte, $n^{\circ}$. $1,2003$.

SILVESTRE, Giane. Dias de visita: uma sociologia da punição e das prisões. 2011. Dissertação (Mestrado em Sociologia) - Universidade Federal de São Carlos, São Paulo, 2011.

SILVESTRE, Giane. Prisões, Sociedade e Punição: As Penitenciárias e suas Relações com o Município de Itirapina. Trabalho de Conclusão de Curso (Graduação em Ciências Sociais) - Faculdade de Filosofia e Ciências, Universidade Estadual Paulista, Marília-SP, 2007. 
SIMONS, Pamela. Strip-Search Women arrested for minor traffic violations have had their bodies probed and their minds mugged. Newsweek, 1979.

SPAGNA, Laisa. "Mulher de bandido": A Construção de Uma Identidade Virtual. Revista dos Estudantes de Direito da UnB, Brasília, v. 7, 2008.

SPOTO, MaryAnn. Cell phone-sniffing dogs used to crack down on N.J. prisoners orchestrating crime from behind bars. NJ Advance Media, Nova Jersey. 12 dez. 2011.

STARCK, Christian (Coord.). Das Bonner Grundgesetz. $4^{\text {a }}$ ed. München: Verlag Franz Vahlen, 1999.

SÜSSEKIND, Elizabeth. Estratégias de Sobrevivência e de Convivência nas Prisões do Rio de Janeiro. 2014. Tese (Doutorado em História) - Centro de Pesquisa e Documentação de História Contemporânea do Brasil CPDOC da Fundação Getúlio Vargas, Rio de Janeiro, 2014.

TELLES, Vera da Silva. Ilegalismos urbanos e a cidade. Novos estudos-CEBRAP, São Paulo, n. 84, 2009.

VILARES, Fernanda; MALAN, Diogo. O Conselho Nacional de Política Criminal e Penitenciária (CNPCP), Boletim do Ibccrim, ano 25, nº 293, abr. 2017.

WANDERMUREM, Marli. Corpo feminino, corpo sedutor, corpo profano: a construção teológica do corpo feminino como simbologia do mal. in Gen. Relig., Salvador, v. 1, n. 1, p. 7-27, jan./jun, 2007.

WELZEL, Hans. Derecho penal aleman: parte general. 4. ed. Santiago: Juridica de Chile, 1993.

ZAFFARONI, Eugenio Raúl; ALAGIA, Alejandro; SLOKAR, Alejandro. Derecho penal: parte general. Buenos Aires: Ediar, 2000.

ZAFFARONI, Eugenio Raúl; BATISTA, Nilo. Direito Penal brasileiro: primeiro volume: teoria geral do Direito Penal. 4. ed. Rio de Janeiro: Revan, 2013.

ZAFFARONI, Eugenio. La Cuestión Criminal. Buenos Aires: Planeta, 2013 
Apêndice A - Decisões do STJ sobre Revista Íntima Catalogadas 


\begin{tabular}{|c|c|c|c|c|c|c|}
\hline \begin{tabular}{|l|} 
Número da \\
Decisão
\end{tabular} & $\begin{array}{l}\text { Como incide a } \\
\text { questão } \\
\text { Revista }\end{array}$ & $\begin{array}{l}\text { Data da } \\
\text { Publicação }\end{array}$ & Origem & Polo Ativo & Polo Passivo & $\begin{array}{l}\text { Houve análise da } \\
\text { Questão da Revista no } \\
\text { Mérito da Decisão? }\end{array}$ \\
\hline $\begin{array}{l}\text { REsp } \\
856360\end{array}$ & Indenização & $23 / 09 / 2008$ & ACRE & $\begin{array}{l}\text { MARAYSA ARAÚJO DE } \\
\text { OLIVEIRA Adv. Particular }\end{array}$ & ESTADO DO ACRE & SIM \\
\hline $\begin{array}{ll}\mathrm{HC} & 218123 \\
(1) & \end{array}$ & $\begin{array}{l}\text { Suspensão da } \\
\text { Revista em } \\
\text { Mulher Grávida }\end{array}$ & 06/09/2011 & $\begin{array}{l}\text { MINAS } \\
\text { GERAIS }\end{array}$ & \begin{tabular}{lll} 
SHEILA & \multicolumn{2}{c}{ CONRRADO } \\
ALVES & SILVA & Adv. \\
Particular & &
\end{tabular} & $\begin{array}{l}\text { TJ DO ESTADO DE } \\
\text { MINAS GERAIS }\end{array}$ & NÃO \\
\hline $\begin{array}{|ll|}\mathrm{HC} & 218123 \\
(2) & \end{array}$ & $\begin{array}{lr}\text { Suspensão da } \\
\text { Revista em } \\
\text { Mulher Grávida }\end{array}$ & $28 / 10 / 2011$ & $\begin{array}{l}\text { MINAS } \\
\text { GERAIS }\end{array}$ & \begin{tabular}{|lrr|} 
SHEILA & \multicolumn{2}{c}{ CONRRADO } \\
ALVES & SILVA & Adv. \\
Particular & &
\end{tabular} & $\begin{array}{l}\text { TJ DO ESTADO DE } \\
\text { MINAS GERAIS }\end{array}$ & NÃO \\
\hline HC 227589 & $\begin{array}{l}\text { Prova ilícita no } \\
\text { Tráfico de Drogas }\end{array}$ & $12 / 12 / 2011$ & $\begin{array}{l}\text { MINAS } \\
\text { GERAIS }\end{array}$ & $\begin{array}{lccc}\text { DP } & \text { DO } & \text { ESTADO } & \text { DE } \\
\text { MINAS GERAIS } & \end{array}$ & $\begin{array}{l}\text { TJ DO ESTADO DE } \\
\text { MINAS GERAIS }\end{array}$ & NÃO \\
\hline $\begin{array}{l}\text { AREsp } \\
115061\end{array}$ & $\begin{array}{l}\text { Prova ilícita no } \\
\text { Tráfico de Drogas }\end{array}$ & $07 / 05 / 2012$ & $\begin{array}{l}\text { RIO GRANDE } \\
\text { DO SUL }\end{array}$ & $\begin{array}{l}\text { MP DO ESTADO DO RIO } \\
\text { GRANDE DO SUL }\end{array}$ & \begin{tabular}{|lll|}
\multicolumn{3}{l}{ DP DO ESTADO DO } \\
RIO & GRANDE & DO \\
SUL & &
\end{tabular} & NÃO \\
\hline HC 245981 & $\begin{array}{l}\text { Pedido r de } \\
\text { progressão para } \\
\text { evitar revista da } \\
\text { família }\end{array}$ & $28 / 06 / 2012$ & $\begin{array}{ll}\text { RIO } & \text { DE } \\
\text { JANEIRO }\end{array}$ & $\begin{array}{ll}\text { SERGIO } & \text { AUGUSTO } \\
\text { BARBOSA } & \text { PINTO Adv. } \\
\text { Particular } & \end{array}$ & $\begin{array}{l}\text { TJ DO ESTADO DO } \\
\text { RIO DE JANEIRO }\end{array}$ & NÃO \\
\hline \begin{tabular}{|l|} 
RHC \\
035358
\end{tabular} & $\begin{array}{l}\text { Prova ilícita no } \\
\text { Tráfico de Drogas }\end{array}$ & $05 / 03 / 2013$ & $\begin{array}{l}\text { MINAS } \\
\text { GERAIS }\end{array}$ & 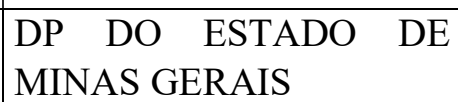 & $\begin{array}{l}\text { TJ DO ESTADO DE } \\
\text { MINAS GERAIS }\end{array}$ & NÃO \\
\hline
\end{tabular}




\begin{tabular}{|c|c|c|c|c|c|c|}
\hline HC 267507 & $\mid \begin{array}{l}\text { Suspensão } \quad \text { da } \\
\text { Revista }\end{array}$ & |10/04/2013 & RONDÔNIA & $\left|\begin{array}{lll}\text { TJ DO ESTADO DE } \\
\text { RONDÔNIA }\end{array}\right|$ & $\left|\begin{array}{lr}\multicolumn{2}{|l}{\text { MARIA APARECIDA }} \\
\text { BERNARDO } & \text { DE } \\
\text { OLIVEIRA } & \text { E } \\
\text { OUTRAS } & \end{array}\right|$ & NÃO \\
\hline $\begin{array}{|ll|}\mathrm{HC} & 273360 \\
(1) & \end{array}$ & $\begin{array}{|ll|}\text { Suspensão } & \text { da } \\
\text { Revista } & \end{array}$ & $05 / 08 / 2013$ & SÃO PAULO & \begin{tabular}{|lr|}
\multicolumn{3}{|l|}{ DP DO ESTADO DE SÃO } \\
PAULO & VISITANTES \\
DAS & UNIDADES \\
PRISIONAIS & DE \\
\multicolumn{2}{l}{ TAUBATÉ - SP }
\end{tabular} & $\begin{array}{l}\text { TJ DO ESTADO DE } \\
\text { SÃO PAULO }\end{array}$ & NÃO \\
\hline $\begin{array}{l}\text { AREsp } \\
351124\end{array}$ & $\begin{array}{l}\text { Prova ilícita no } \\
\text { Tráfico de Drogas }\end{array}$ & $27 / 08 / 2013$ & $\begin{array}{l}\text { RIO GRANDE } \\
\text { DO SUL }\end{array}$ & $\begin{array}{l}\text { MP DO ESTADO DO RIO } \\
\text { GRANDE DO SUL }\end{array}$ & $\mid$\begin{tabular}{lll}
\multicolumn{2}{l}{ DP DO ESTADO DO } \\
RIO & GRANDE & DO \\
SUL & &
\end{tabular} & NÃO \\
\hline $\begin{array}{l}\text { AREsp } \\
096074\end{array}$ & \begin{tabular}{|l|} 
Prova ilícita no \\
Tráfico de Drogas
\end{tabular} & $07 / 10 / 2013$ & $\begin{array}{l}\text { RIO GRANDE } \\
\text { DO SUL }\end{array}$ & $\begin{array}{l}\text { MP DO ESTADO DO RIO } \\
\text { GRANDE DO SUL }\end{array}$ & $\mid$\begin{tabular}{lll}
\multicolumn{2}{l}{ DP DO ESTADO DO } \\
RIO & GRANDE & DO \\
SUL & &
\end{tabular} & NÃO \\
\hline $\begin{array}{ll}\mathrm{HC} & 273360 \\
(2) & \end{array}$ & $\begin{array}{l}\text { Suspensão } \quad \text { da } \\
\text { Revista }\end{array}$ & $25 / 04 / 2014$ & SÃO PAULO & \begin{tabular}{|lr}
\multicolumn{3}{l}{ DP DO ESTADO DE SÃO } \\
PAULO & VISITANTES \\
DAS & UNIDADES \\
PRISIONAIS & DE \\
\multicolumn{2}{l}{ TAUBATÉ - SP }
\end{tabular} & $\begin{array}{l}\text { TJ DO ESTADO DE } \\
\text { SÃO PAULO }\end{array}$ & NÃO \\
\hline \begin{tabular}{|l|} 
RMS \\
044797
\end{tabular} & $\begin{array}{l}\text { Revista em menor } \\
\text { de idade }\end{array}$ & $27 / 05 / 2014$ & SÃO PAULO & $\begin{array}{l}\text { DP DO ESTADO DE SÃO } \\
\text { PAULO }\end{array}$ & $\begin{array}{l}\text { MP DO ESTADO DE } \\
\text { SÃO PAULO }\end{array}$ & NÃO \\
\hline HC 197394 & $\begin{array}{l}\text { Prova ilícita no } \\
\text { Tráfico de Drogas }\end{array}$ & $17 / 06 / 2014$ & $\begin{array}{ll}\text { RIO } & \text { DE } \\
\text { JANEIRO }\end{array}$ & $\begin{array}{l}\text { DP DO ESTADO DO RIO } \\
\text { DE JANEIRO }\end{array}$ & $\begin{array}{l}\text { TJ DO ESTADO DO } \\
\text { RIO DE JANEIRO }\end{array}$ & NÃO \\
\hline
\end{tabular}




\begin{tabular}{|c|c|c|c|c|c|c|}
\hline HC 233336 & $\left|\begin{array}{l}\text { Prova ilícita no } \\
\text { Tráfico de Drogas }\end{array}\right|$ & |01/08/2014 & SÃO PAULO & $\begin{array}{l}\text { DP DO ESTADO DE SÃO } \\
\text { PAULO }\end{array}$ & $\left|\begin{array}{l}\text { TJ DO ESTADO DE } \\
\text { SÃO PAULO }\end{array}\right|$ & NÃO \\
\hline $\begin{array}{l}\mathrm{HC} \\
\text { (2) }\end{array}$ & $\begin{array}{l}\text { Prova ilícita no } \\
\text { Tráfico de Drogas }\end{array}$ & $28 / 08 / 2014$ & SÃO PAULO & $\begin{array}{l}\text { DP DO ESTADO DE SÃO } \\
\text { PAULO }\end{array}$ & $\begin{array}{l}\text { TJ DO ESTADO DE } \\
\text { SÃO PAULO }\end{array}$ & NÃO \\
\hline \begin{tabular}{|l|} 
REsp \\
1457053
\end{tabular} & Crime Impossível & $18 / 09 / 2014$ & $\begin{array}{l}\text { RIO GRANDE } \\
\text { DO SUL }\end{array}$ & $\begin{array}{l}\text { MP DO ESTADO DO RIO } \\
\text { GRANDE DO SUL }\end{array}$ & $\begin{array}{|lr|}\text { ANA } & \text { MADALENA } \\
\text { DE } & \text { OLIVEIRA } \\
\text { VIEIRA } & \text { BENTO } \\
\text { DPRS } & \end{array}$ & SIM \\
\hline $\begin{array}{l}\text { AREsp } \\
565138\end{array}$ & Indenização & $23 / 09 / 2014$ & BAHIA & ESTADO DA BAHIA & $\begin{array}{l}\text { DP DO ESTADO DA } \\
\text { BAHIA }\end{array}$ & NÃO \\
\hline HC 306995 & \begin{tabular}{|l|} 
Prova ilícita no \\
Tráfico de Drogas
\end{tabular} & $20 / 10 / 2014$ & SÃO PAULO & $\begin{array}{l}\text { DP DO ESTADO DO RIO } \\
\text { GRANDE DO SUL }\end{array}$ & $\begin{array}{|lll|}\text { TJ DO ESTADO } & \text { DO } \\
\text { RIO } & \text { GRANDE } & \text { DO } \\
\text { SUL } & & \end{array}$ & NÃO \\
\hline HC 299337 & $\begin{array}{l}\text { Prova ilícita no } \\
\text { Tráfico de Drogas }\end{array}$ & $29 / 10 / 2014$ & $\begin{array}{l}\text { SANTA } \\
\text { CATARINA }\end{array}$ & 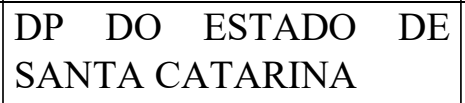 & $\begin{array}{l}\text { TJ DO ESTADO DE } \\
\text { SANTA CATARINA }\end{array}$ & NÃO \\
\hline $\begin{array}{l}\text { REsp } \\
1458025\end{array}$ & $\begin{array}{l}\text { Prova ilícita no } \\
\text { Tráfico de Drogas }\end{array}$ & $07 / 11 / 2014$ & $\begin{array}{l}\text { RIO GRANDE } \\
\text { DO SUL }\end{array}$ & $\begin{array}{l}\text { MP DO ESTADO DO RIO } \\
\text { GRANDE DO SUL }\end{array}$ & $\begin{array}{|lr|}\text { LEIDI } & \text { VALÉRIA } \\
\text { FERREIRA } & \text { Adv. } \\
\text { Particular } & \\
\end{array}$ & NÃO \\
\hline $\begin{array}{l}\text { REsp } \\
1386983\end{array}$ & \begin{tabular}{|l|} 
Prova ilícita no \\
Tráfico de Drogas
\end{tabular} & $21 / 11 / 2014$ & $\begin{array}{l}\text { RIO GRANDE } \\
\text { DO SUL }\end{array}$ & $\begin{array}{l}\text { MP DO ESTADO DO RIO } \\
\text { GRANDE DO SUL }\end{array}$ & \begin{tabular}{|lll|}
\multicolumn{3}{|l}{ DP DO ESTADO DO } \\
RIO & GRANDE & DO \\
SUL & &
\end{tabular} & NÃO \\
\hline $\begin{array}{l}\mathrm{HC} 310907 \\
(1)\end{array}$ & $\begin{array}{l}\text { Prova ilícita no } \\
\text { Tráfico de Drogas }\end{array}$ & $12 / 12 / 2014$ & SÃO PAULO & $\begin{array}{l}\text { DP DO ESTADO DE SÃO } \\
\text { PAULO }\end{array}$ & $\begin{array}{l}\text { TJ DO ESTADO DE } \\
\text { SÃO PAULO }\end{array}$ & NÃO \\
\hline
\end{tabular}




\begin{tabular}{|c|c|c|c|c|c|c|}
\hline $\begin{array}{ll}\mathrm{HC} & 301782 \\
(1) & \end{array}$ & $\begin{array}{l}\text { Prova ilícita no } \\
\text { Tráfico de Drogas }\end{array}$ & |04/02/2015 & SÃO PAULO & $\begin{array}{l}\text { DP DO ESTADO DE SÃO } \\
\text { PAULO }\end{array}$ & $\left|\begin{array}{l}\text { TJ DO ESTADO DE } \\
\text { SÃO PAULO }\end{array}\right|$ & NÃO \\
\hline $\begin{array}{l}\text { REsp } \\
1442870\end{array}$ & Crime Impossível & $04 / 02 / 2015$ & $\begin{array}{l}\text { RIO GRANDE } \\
\text { DO SUL }\end{array}$ & $\begin{array}{l}\text { MP DO ESTADO DO RIO } \\
\text { GRANDE DO SUL }\end{array}$ & \begin{tabular}{|l|} 
MARIANE \\
FERNANDES \\
CONCEIÇÃO Adv. \\
Particular
\end{tabular} & SIM \\
\hline HC 315164 & $\begin{array}{l}\text { Prova ilícita no } \\
\text { Tráfico de Drogas }\end{array}$ & $09 / 02 / 2015$ & $\begin{array}{l}\text { MINAS } \\
\text { GERAIS }\end{array}$ & $\begin{array}{l}\text { ALESSANDRO FELIX } \\
\text { Adv. Particular }\end{array}$ & $\begin{array}{l}\text { TJ DO ESTADO DE } \\
\text { MINAS GERAIS }\end{array}$ & NÃO \\
\hline HC 315372 & $\begin{array}{l}\text { Prova ilícita no } \\
\text { Tráfico de Drogas }\end{array}$ & $09 / 02 / 2015$ & $\begin{array}{l}\text { RIO GRANDE } \\
\text { DO SUL }\end{array}$ & $\begin{array}{lr}\text { MICHELE } & \text { DE } \\
\text { CARVALHO } & \text { Adv. } \\
\text { Particular } & \\
\end{array}$ & 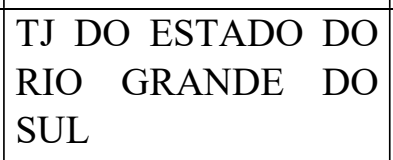 & NÃO \\
\hline $\begin{array}{l}\text { REsp } \\
1509601\end{array}$ & $\begin{array}{l}\text { Prova ilícita no } \\
\text { Tráfico de Drogas }\end{array}$ & $19 / 03 / 2015$ & $\begin{array}{l}\text { RIO GRANDE } \\
\text { DO SUL }\end{array}$ & $\begin{array}{l}\text { MP DO ESTADO DO RIO } \\
\text { GRANDE DO SUL }\end{array}$ & \begin{tabular}{|lll|}
\multicolumn{3}{l}{ DP DO ESTADO DO } \\
RIO & GRANDE & DO \\
SUL & &
\end{tabular} & SIM \\
\hline $\begin{array}{l}\text { REsp } \\
1508762\end{array}$ & $\begin{array}{l}\text { Prova ilícita no } \\
\text { Tráfico de Drogas }\end{array}$ & $31 / 03 / 2015$ & $\begin{array}{l}\text { RIO GRANDE } \\
\text { DO SUL }\end{array}$ & $\begin{array}{l}\text { MP DO ESTADO DO RIO } \\
\text { GRANDE DO SUL }\end{array}$ & \begin{tabular}{|lll|}
\multicolumn{3}{l}{ DP DO ESTADO DO } \\
RIO & GRANDE & DO \\
SUL & &
\end{tabular} & SIM \\
\hline HC 321310 & $\begin{array}{l}\text { Prova ilícita no } \\
\text { Tráfico de Drogas }\end{array}$ & $20 / 04 / 2015$ & SÃO PAULO & $\begin{array}{l}\text { DP DO ESTADO DE SÃO } \\
\text { PAULO }\end{array}$ & $\begin{array}{l}\text { TJ DO ESTADO DE } \\
\text { SÃO PAULO }\end{array}$ & NÃO \\
\hline HC 323298 & $\begin{array}{l}\text { Prova ilícita no } \\
\text { Tráfico de Drogas }\end{array}$ & $20 / 05 / 2015$ & SÃO PAULO & $\begin{array}{l}\text { DP DO ESTADO DE SÃO } \\
\text { PAULO }\end{array}$ & $\begin{array}{l}\text { TJ DO ESTADO DE } \\
\text { SÃO PAULO }\end{array}$ & NÃO \\
\hline HC 328378 & $\begin{array}{l}\text { Prova ilícita no } \\
\text { Tráfico de Drogas }\end{array}$ & $05 / 08 / 2015$ & SÃO PAULO & $\begin{array}{l}\text { DP DO ESTADO DE SÃO } \\
\text { PAULO }\end{array}$ & $\begin{array}{l}\text { TJ DO ESTADO DE } \\
\text { SÃO PAULO }\end{array}$ & NÃO \\
\hline
\end{tabular}




\begin{tabular}{|c|c|c|c|c|c|c|}
\hline $\begin{array}{l}\text { HC } 328843 \\
\text { (1) }\end{array}$ & $\begin{array}{l}\text { Prova ilícita no } \\
\text { Tráfico de Drogas }\end{array}$ & |06/08/2015 & SÃO PAULO & $\begin{array}{l}\text { DP DO ESTADO DE SÃO } \\
\text { PAULO }\end{array}$ & $\begin{array}{l}\text { TJ DO ESTADO DE } \\
\text { SÃO PAULO }\end{array}$ & SIM \\
\hline $\begin{array}{l}\text { REsp } \\
1519468\end{array}$ & Crime Impossível & $06 / 08 / 2015$ & $\begin{array}{l}\text { RIO GRANDE } \\
\text { DO SUL }\end{array}$ & $\begin{array}{l}\text { MP DO ESTADO DO RIO } \\
\text { GRANDE DO SUL }\end{array}$ & \begin{tabular}{lll}
\multicolumn{2}{l}{ DP DO ESTADO DO } \\
RIO & GRANDE & DO \\
SUL & &
\end{tabular} & SIM \\
\hline $\begin{array}{l}\text { REsp } \\
1533642\end{array}$ & Crime Impossível & $06 / 08 / 2015$ & $\begin{array}{ll}\text { RIO DE } \\
\text { JANEIRO }\end{array}$ & $\begin{array}{l}\text { DP DO ESTADO DO RIO } \\
\text { DE JANEIRO }\end{array}$ & $\begin{array}{l}\text { MP DO ESTADO DO } \\
\text { RIO DE JANEIRO }\end{array}$ & NÃO \\
\hline $\begin{array}{l}\text { HC } 310907 \\
\text { (2) }\end{array}$ & $\begin{array}{l}\text { Prova ilícita no } \\
\text { Tráfico de Drogas }\end{array}$ & $19 / 08 / 2015$ & SÃO PAULO & $\begin{array}{l}\text { DP DO ESTADO DE SÃO } \\
\text { PAULO }\end{array}$ & $\begin{array}{l}\text { TJ DO ESTADO DE } \\
\text { SÃO PAULO }\end{array}$ & NÃO \\
\hline $\begin{array}{l}\text { HC } 332330 \\
\text { (1) }\end{array}$ & $\begin{array}{l}\text { Prova ilícita no } \\
\text { Tráfico de Drogas }\end{array}$ & $24 / 08 / 2015$ & $\begin{array}{l}\text { RIO GRANDE } \\
\text { DO SUL }\end{array}$ & $\begin{array}{l}\text { DP DO ESTADO DO RIO } \\
\text { GRANDE DO SUL }\end{array}$ & $\begin{array}{lll}\text { TJ DO ESTADO DO } \\
\text { RIO } & \text { GRANDE } & \text { DO } \\
\text { SUL } & & \end{array}$ & NÃO \\
\hline HC 332396 & $\begin{array}{l}\text { Prova ilícita no } \\
\text { Tráfico de Drogas }\end{array}$ & $25 / 08 / 2015$ & SÃO PAULO & $\begin{array}{l}\text { DP DO ESTADO DE SÃO } \\
\text { PAULO }\end{array}$ & $\begin{array}{l}\text { TJ DO ESTADO DE } \\
\text { SÃO PAULO }\end{array}$ & NÃO \\
\hline $\begin{array}{l}\text { REsp } \\
1539278\end{array}$ & Crime Impossível & $26 / 08 / 2015$ & $\begin{array}{l}\text { RIO GRANDE } \\
\text { DO SUL }\end{array}$ & $\begin{array}{l}\text { MP DO ESTADO DO RIO } \\
\text { GRANDE DO SUL }\end{array}$ & \begin{tabular}{lll}
\multicolumn{3}{l}{ DP DO ESTADO DO } \\
RIO GRANDE DO \\
SUL
\end{tabular} & SIM \\
\hline $\begin{array}{l}\text { AREsp } \\
712339\end{array}$ & $\begin{array}{l}\text { Prova ilícita no } \\
\text { Tráfico de Drogas }\end{array}$ & $04 / 09 / 2015$ & $\begin{array}{l}\text { MINAS } \\
\text { GERAIS }\end{array}$ & 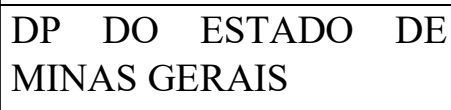 & $\begin{array}{l}\text { MP DO ESTADO DE } \\
\text { MINAS GERAIS }\end{array}$ & NÃO \\
\hline HC 335568 & $\begin{array}{l}\text { Prova ilícita no } \\
\text { Tráfico de Drogas }\end{array}$ & $14 / 09 / 2015$ & SÃO PAULO & $\begin{array}{l}\text { ELIANE DE SOUZA } \\
\text { SILVA Adv. Particular }\end{array}$ & $\begin{array}{l}\text { TJ DO ESTADO DE } \\
\text { SÃO PAULO }\end{array}$ & NÃO \\
\hline
\end{tabular}




\begin{tabular}{|c|c|c|c|c|c|c|}
\hline $\begin{array}{ll}\mathrm{HC} & 328843 \\
(2) & \end{array}$ & $\begin{array}{l}\text { Prova ilícita no } \\
\text { Tráfico de Drogas }\end{array}$ & |09/11/2015 & SÃO PAULO & $\begin{array}{l}\text { DP DO ESTADO DE SÃO } \\
\text { PAULO }\end{array}$ & $\begin{array}{l}\text { MP DO ESTADO DE } \\
\text { SÃO PAULO }\end{array}$ & SIM \\
\hline $\begin{array}{ll}\text { HC } & 332330 \\
(2) & \end{array}$ & $\begin{array}{l}\text { Prova ilícita no } \\
\text { Tráfico de Drogas }\end{array}$ & $25 / 11 / 2015$ & $\begin{array}{l}\text { RIO GRANDE } \\
\text { DO SUL }\end{array}$ & $\begin{array}{l}\text { DP DO ESTADO DO RIO } \\
\text { GRANDE DO SUL }\end{array}$ & \begin{tabular}{lll}
\multicolumn{2}{l}{ TJ DO ESTADO DO } \\
RIO & GRANDE & DO \\
SUL & &
\end{tabular} & NÃO \\
\hline HC 344121 & $\begin{array}{l}\text { Prova ilícita no } \\
\text { Tráfico de Drogas }\end{array}$ & $09 / 12 / 2015$ & $\begin{array}{l}\text { RIO GRANDE } \\
\text { DO SUL }\end{array}$ & $\begin{array}{l}\text { DP DO ESTADO DO RIO } \\
\text { GRANDE DO SUL }\end{array}$ & $\begin{array}{lll}\text { TJ DO ESTADO DO } \\
\text { RIO } & \text { GRANDE } & \text { DO } \\
\text { SUL } & & \end{array}$ & SIM \\
\hline HC 343994 & $\begin{array}{l}\text { Prova ilícita no } \\
\text { Tráfico de Drogas }\end{array}$ & $16 / 12 / 2015$ & SÃO PAULO & $\begin{array}{l}\text { DP DO ESTADO DE SÃO } \\
\text { PAULO }\end{array}$ & $\begin{array}{l}\text { TJ DO ESTADO DE } \\
\text { SÃO PAULO }\end{array}$ & NÃO \\
\hline \begin{tabular}{|l|} 
REsp \\
1575522
\end{tabular} & Crime Impossível & $18 / 02 / 2016$ & SÃO PAULO & $\begin{array}{l}\text { DP DO ESTADO DE SÃO } \\
\text { PAULO }\end{array}$ & $\begin{array}{l}\text { MP DO ESTADO DE } \\
\text { SÃO PAULO }\end{array}$ & SIM \\
\hline \begin{tabular}{|l|} 
REsp \\
1458024
\end{tabular} & Crime Impossível & $25 / 02 / 2016$ & $\begin{array}{l}\text { RIO GRANDE } \\
\text { DO SUL }\end{array}$ & $\begin{array}{l}\text { MP DO ESTADO DO RIO } \\
\text { GRANDE DO SUL }\end{array}$ & \begin{tabular}{|lll}
\multicolumn{3}{l}{ DP DO ESTADO DO } \\
RIO & GRANDE & DO \\
SUL & & \\
\end{tabular} & SIM \\
\hline HC 341021 & $\begin{array}{l}\text { Prova ilícita no } \\
\text { Tráfico de Drogas }\end{array}$ & $31 / 03 / 2016$ & $\begin{array}{l}\text { RIO GRANDE } \\
\text { DO SUL }\end{array}$ & $\begin{array}{l}\text { DP DO ESTADO DO RIO } \\
\text { GRANDE DO SUL }\end{array}$ & 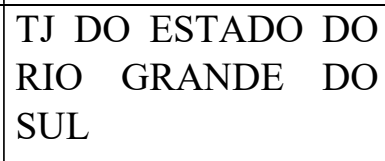 & NÃO \\
\hline $\begin{array}{l}\text { REsp } \\
1577957\end{array}$ & Crime Impossível & $20 / 04 / 2016$ & $\begin{array}{l}\text { RIO GRANDE } \\
\text { DO SUL }\end{array}$ & $\begin{array}{l}\text { MP DO ESTADO DO RIO } \\
\text { GRANDE DO SUL }\end{array}$ & \begin{tabular}{lll}
\multicolumn{3}{l}{ DP DO ESTADO DO } \\
RIO & GRANDE & DO \\
SUL & &
\end{tabular} & SIM \\
\hline
\end{tabular}




\begin{tabular}{|l|l|l|l|l|l|l|} 
HC 355229 & $\begin{array}{l}\text { Prova ilícita no } \\
\text { Tráfico de Drogas }\end{array}$ & $26 / 04 / 2016$ & SÃO PAULO & $\begin{array}{l}\text { DP DO ESTADO DE SÃO } \\
\text { PAULO }\end{array}$ & $\begin{array}{l}\text { TJ DO ESTADO DE } \\
\text { SÃO PAULO }\end{array}$ & NÃO \\
\hline HC 359020 & $\begin{array}{l}\text { Prova ilícita no no } \\
\text { Tráfico de Drogas }\end{array}$ & $02 / 06 / 2016$ & PARANÁ & $\begin{array}{l}\text { DP DO ESTADO DO } \\
\text { PARANÁ }\end{array}$ & $\begin{array}{l}\text { TJ DO ESTADO DO NÃO } \\
\text { PARANÁ }\end{array}$ & NANO \\
\hline
\end{tabular}




\section{Apêndice B - Questionário Semiestruturado}

\section{Parte 1- Perguntas Iniciais}

Nome:

Idade:

Local onde reside:

Você faz visitas aqui no CDP há quanto tempo?

Você já visitou em outros lugares?

\section{Parte 2 - Sobre o Dia de Visita}

Como é normalmente um dia de visita? Que horas você precisa chegar? O que costuma trazer?

Você vem sozinha ou acompanhada? Conhece alguém aqui na fila que visite também?
Algum parente ou amigo ajuda na preparação do Jumbo?
É caro "montar" o Jumbo? E fazer a visita?
O que você acha mais difícil da visita? Qual são suas maiores dificuldades?

\section{Parte 3- Sobre a Relação com a Revista}

Você se importa se conversarmos sobre a Revista?

Como que ela [a Revista] funciona aqui?

Ela [a Revista] sempre foi feita assim?

Nos outros lugares que você visitou era diferente?

Você soube de alguma notícia sobre a revista ter sido proibida?

Você sabe de algum lugar que não tem mais revista íntima? Como é feito lá?

Você acha que é possível acabar com a revista do jeito que ela é feita?

[No caso dos CDPs de Pinheiros, se for concretizada a instalação dos escâneres] Como é a revista agora?

Todas as pessoas passam pelo escâner do mesmo jeito? Ou alguém é revistado do jeito que era antes?

Como que foi essa mudança para você? Como você soube que ela ia mudar? 


\section{Apêndice C - Modelo de Termo de Consentimento Livre e Esclarecido}

\section{TERMO DE CONSENTIMENTO LIVRE E ESCLARECIDO}

Elaborado de acordo com as diretrizes da Res. n 510/2016 do Conselho Nacional de Saúde

Na data de hoje, a Senhora/o Senhor foi Convidada para participar da Pesquisa " $A$ Revista Íntima em estabelecimentos prisionais: superação de uma prática violadora no Estado de São Paulo" que é parte de pesquisa de Mestrado da Faculdade de Direito da Universidade de São Paulo.

Todas as informações que foram ditas são anônimas e seu nome não será divulgado para nenhuma outra pessoa.

Sua participação é voluntária e gratuita.

A Senhora/o Senhor pode desistir a qualquer momento da participação e pedir que tudo o que disse não seja usado.

Se a Senhora/o Senhor tiver qualquer problema psicológico em razão da sua participação na pesquisa, o devido cuidado pode ser recebido no CAPS - Centro de Atenção Psicossocial mais próximo a sua residência. A lista completa dos CAPS com endereços e telefones está disponível nesse site: https://www.spdm.org.br/images/stories/unidades/CAPs_SP.pdf.

Para qualquer dúvida ou esclarecimento, entre em contato com Bruna Diniz, a pesquisadora com quem a Senhora/o Senhor conversou hoje no e-mail: revistaintimadiniz@gmail.com.

LOCAL, DATA, ASSINATURA,

NOME E DOCUMENTO DE IDENTIFICAÇÃO 